\title{
EKSTRAKSI FITUR MENGGUNAKAN MODEL WORD2VEC PADA SENTIMENT ANALYSIS KOLOM KOMENTAR KUISIONER EVALUASI DOSEN OLEH MAHASISWA
}

\author{
Muhammad Rusli', Mohammad Reza Faisal' ${ }^{2}$ Irwan Budiman ${ }^{3}$, \\ Radityo Adi Nugroho ${ }^{4}$, Andi Farmadi ${ }^{5}$ \\ Prodi Ilmu Komputer FMIPA ULM \\ Jl. A. Yani Km 36 Banjarbaru, Kalimantan Selatan \\ Email: rusli150397@gmail.com
}

\begin{abstract}
This research is about Sentiment Analysis using the Word2vec model. this research was conducted by Fauzi (2019). But in his research the use of the Word2vec model produces an accuracy of 70\%, because the data used is small. In little data Word2vec cannot grasp the similarity of meaning well. So that related research was conducted which used lecturer evaluation comment data and also Wikipedia article data in Indonesian language as Word2vec model. In this study a comparison of average extraction features of Word2vec and Bag of Centroid base Word2vec was done and a combination of the two was then performed using the Support Vector Machine method. The application of Word2vec Average base feature extraction in the lecturer evaluation commentary data resulted in an accuracy of $84,8 \%$. Then using the Bag of Centroid base feature extraction using Word2vec Hierarchy Clustering produces the best accuracy of $81,6 \%$ with a total of 75 features. The result of merging the two feature extractions produces an accuracy of $85,3 \%$.
\end{abstract}

Keywords: Sentiment Analysis, Word2vec, Feature extraction

\begin{abstract}
Abstrak
Penelitian ini mengenai Sentiment Analysis menggunakan model Word2vec. penelitian ini pernah dilakukan oleh Fauzi (2019). Namun pada penelitiannya penggunaan model Word2vec menghasilkan akurasi 70\%, karena data yang digunakan sedikit. Dalam data yang sedikit Word2vec tidak dapat menangkap kemiripan makna dengan baik. Sehingga dilakukan penelitian terkait yang mana menggunakan data komentar evaluasi dosen dan juga data artikel Wikipedia berbahasa Indonesia sebagai model Word2vec. Pada penelitian ini dilakukan perbandingan ekstraksi fitur Average base Word2vec dan Bag of Centroid base Word2vec dan juga dilakukan penggabungan keduanya kemudian dilakukan klasifikasi menggunakan metode Support Vector Machine. Penerapan ekstraksi fitur Average base Word2vec pada data komentar evaluasi dosen menghasilkan akurasi sebesar 84,8\%. Kemudian menggunakan ekstraksi fitur Bag of Centroid base Word2vec menggunakan Hirarki Clustering menghasilkan akurasi terbaik sebesar 81,6\% dengan jumlah 75 fitur. Hasil penggabungan kedua ekstraksi fitur menghasilkan akurasi sebesar 85,3\%.
\end{abstract}

Kata kunci: Sentiment Analysis, Word2vec, Ekstraksi fitur. 


\section{PENDAHULUAN}

Sentiment Analysis merupakan cabang penelitian dari Text Mining yang berguna untuk mengklasifikasi dokumen teks berupa opini berdasarkan sentimen. Tugas dasar Sentiment Analysis adalah mengklasifikasikan beberapa teks dari dokumen, kalimat atau fitur, kalimat dari fitur tersebut bisa bersifat positif, negatif dan netral. Pada tahapan Sentiment Analysis terdapat extraksi fitur yang beguna mengubah teks menjadi data yang dapat diklasifikasi.

Ada banyak cara dalam ekstraksi fitur seperti TF, TF-IDF, Lexical Description, Unigram, Bigram dan sebagainya. Pada beberapa penelitian Word2vec digunakan dalam melakukan ekstraksi fitur. Word2vec merupakan algoritma word embedding, yaitu pemetaan dari kata menjadi vector. Vector ini nantinya digunakan untuk berbagai macam tugas Natural Language Processing. Pada Word2vec dalam pembobotan kata digunakan nilai rata-rata vector yang mewakili kata tersebut. Pada penelitian Fauzi [1] mengenai Sentiment Analysis menggunakan model Word2vec menghasilkan akurasi 70\%, hal ini karena data yang digunakan dalam data pelatihan Word2vec sedikit. Dalam data yang kecil, Word2vec tidak dapat menangkap kata-kata yang mirip dengan baik.

Rossiello [2], pada penelitiannya mengusulkan metode berbasis centroid untuk peringkasan teks dalam ekploitasi kemampuan Word Embedding. Pada penelitian tersebut menggunakan metode Word2vec dalam mempelajari hubungan semantik antar kata, kemudian dikluster menjadi beberapa centroid yang mana akan terkumpul berdasarkan kemiripan makna yang dianggapnya sama. Pada penelitian tersebut menghasilkan kinerja yang lebih baik dibandingkan dengan model pembelajaran yang lebih kompleks.

Berdasarkan penelitian Rossiello [2], perlu dilakukan penelitian terkait menggunakan centroid base Word2vec dalam ekstraksi fitur yang akan digunakan dalam klasifikasi Sentiment Analysis yang mana akan kita bandingkan tingkatakurasinya dengan ekstraksi fitur menggunakan Average base Word2vec. Pada penelitian mengenai ekstraksi fitur kadang dilakukan penggabungan beberapa proses ekstraksi fitur untuk mendapatkan informasi yang lebih lengkap, Sehingga perlu dilakukan penelitian juga bagaimana tingkat akurasi ekstraksi fitur dalam Sentiment Analysis jika Bag of Centroid base Word2vec dan Average base Word2vec digabung dalam melakukan ekstraksi fitur.

Pada penelitian ini digunakan metode SVM dalam klasifikasi Sentiment Analysis karena pada beberapa penelitian sebelumnya menghasilkan tingkat akurasi yang sangat baik. Untuk data dalam pembelajaran Word2vec digunakan corpus Wikipedia dan isi komentar pada kuisioner evaluasi dosen yang ada pada portal mahasiswa FMIPA ULM tahun ajaran 2017/2018 semester genap. 


\section{METODOLOGI PENELITIAN}

Adapun prosedur penelitian ini adalah sebagai berikut:

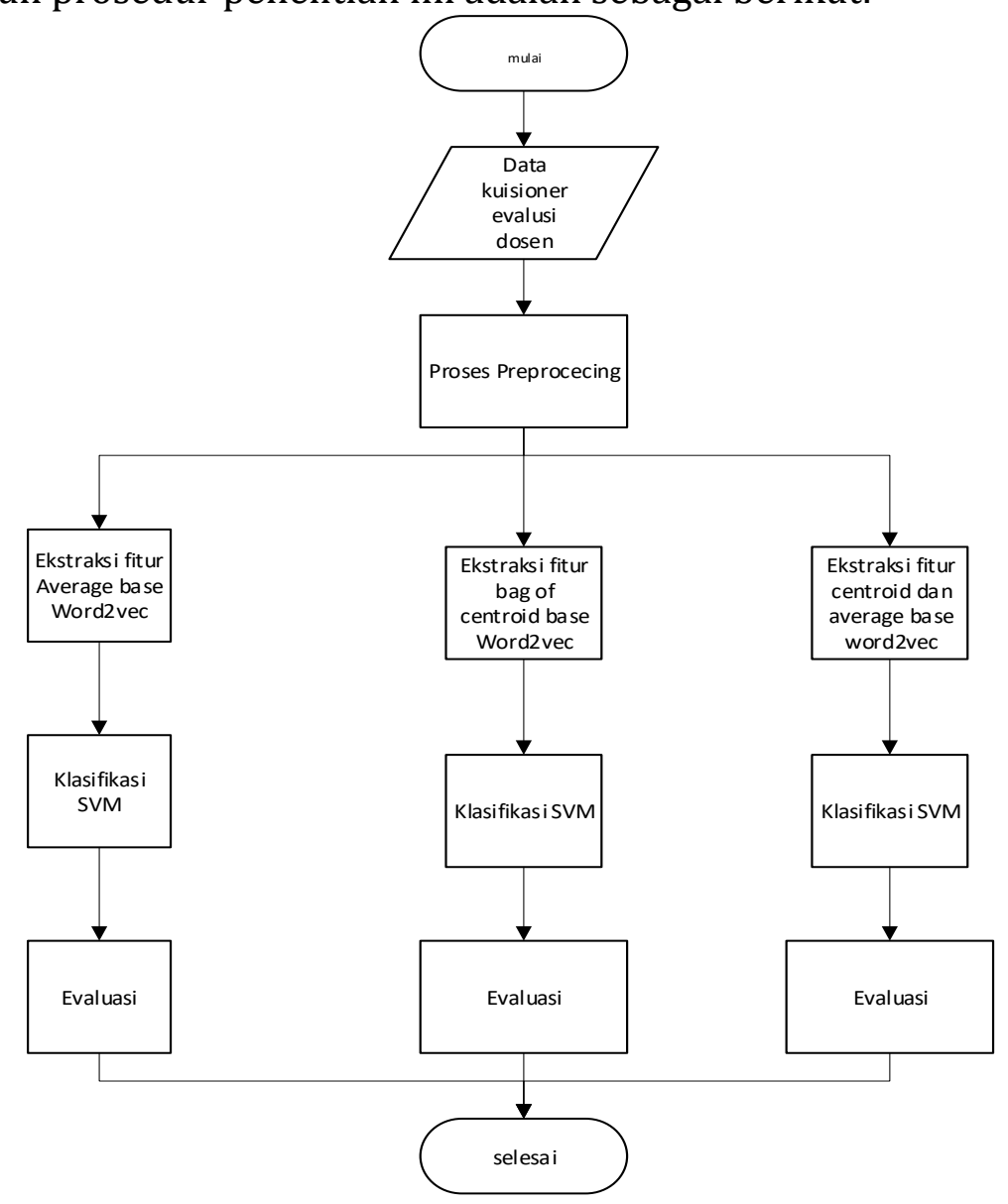

\section{$2.1 \quad$ Pengumpulan Data}

Gambar 1. Alur Penelitian

Data yang digunakan pada penelitian ini yaitu data kolom komentar evaluasi dosen oleh mahasiswa semester genap tahun ajaran 2017/2018 FMIPA ULM dengan jumlah 9154 data.

\subsection{Preprocessing}

Dari semua data, teks adalah bentuk yang paling tidak terstruktur sehingga kita harus melakukan banyak pembersihan. Langkah-langkah preprocessing ini membantu mengubah noise dari fitur dimensi tinggi ke ruang dimensi rendah untuk memperoleh informasi seakurat mungkin dari teks. Yang mana langkah preprocessing sebagai berikut :

a. Data Cleaning

Proses mendeteksi dan memperbaiki atau menghapus data yang rusak atau tidak akurat agar dapat menambah akurasi proses klasifikasi.

b. Removing

Menghapus karakter-karakter yang tidak berkontribusi pada sentiment analysis sehingga hanya menyisakan karakter alfabet. 
c. Case folding

Mengubah setiap kata menjadi kedalam bentuk yang standar, huruf kapital (upper case) atau huruf kecil (lower case).

d. Ekstraksi Fitur

Proses mengubah data teks yang tidak terstruktur menjadi data yang lebih terstruktur, sehingga data tersebut dapat diklasifikasi.

\subsection{Data Mining}

Data mining dilakukan untuk menemukan suatu pola atau informasi dari data yang tersimpan dalam jumlah yang besar dengan menggunakan teknik atau metode tertentu. Pada penelitian ini dilakukan klasifikasi menggunakan Support Vector Machine dan ekstraksi fitur menggunakan model Word2vec untuk Sentiment Analysis.

\subsection{Evaluation}

Evaluation merupakan tahapan penilaian hasil dari teknik data mining yang telah dilakukan sebelumnya.

\section{HASIL DAN PEMBAHASAN \\ 3.1 Hasil}

\subsubsection{Pengumpulan Data}

Data yang digunakan pada penelitian ini yaitu data kolom komentar evaluasi dosen oleh mahasiswa semester genap tahun ajaran 2017/2018 FMIPA ULM dengan jumlah 9154 data. Selain data komentar juga digunakan data artikel Wikipedia yang berjumlah 36000 data. Data komentar dan data artikel digunakan sebagai korpus pada model Word2vec.

\subsubsection{Preprocessing}

Preprocessing pada penelitian ini yaitu penghapusan simbol atau removing, Case Folding, data cleaning. Penghapusan simbol (Removing) merupakan proses menghapus karakter karakter yang tidak perlu. Penghapusan simbol-simbol berfungsi untuk menghapus karakter khusus dalam komentar seperti tanda baca (seperti: koma (,), titik(.), tanda tanya (?), tanda seru (!) dan sebagainya), angka numerik (0 - 9), dan karakter lainnya(seperti: \$, \%, *, dan sebagainya). Setelah melalui tahapan removing, tahapan preprocessing selanjutnya yaitu case folding. Case folding adalah tahapan mengkonversi keseluruhan teks dalam dokumen menjadi suatu bentuk yang standar. Pada penelitian ini case folding digunakan untuk mengubah semua kata mencadi huruf kecil (lowercase). Kemudian tahapan preprocessing selanjutnya yaitu data cleaning. Data cleaning pada penelitian ini yaitu menghapus data yang tidak berkontribusi pada saat klasifikasi agar mengingkatkan hasil akurasi. Adapun data cleaning disini menghapus komentar yang sama, menghapus komentar yang hanya karakter dan tidak menunjukan sentimen. Setelah data melalui tahapan preprocessing diperoleh data sebanyak 2823 data komentar. Dari 2823 data komentar, terdapat 1242 data komentar positif dan juga 1581 data komentar negatif. 


\subsubsection{Pembuatan Model Word2vec}

Pembuatan model word2vec ini berguna untuk menjadikan setiap kata pada data yang kita miliki menjadi vector. Vector pada model word2vec dapat ditentukan jumlah fiturnya. Pada penelitian ini dibuat model word2vec dengan jumlah fitur 100, karena default dari word2vec dengan jumlah fitur 100.

Data artikel Wikipedia dalam bentuk data .txt, Kemudian dengan bantuan package Gensim pada bahasa pemrograman Python terbantuk model word2vec dengan jumlah fitur 100. Adapun contoh model yang dihasilkan pada tabel 1.

Tabel 1. Vector model Word2vec

\begin{tabular}{lccc}
\hline Kata & $\mathrm{v} 1$ & $\mathrm{v} .$. & $\mathrm{v} 100$ \\
\hline baik & -3.380503 & -2.8598306 & 2.4271312 \\
dan & 1.9481431 & -0.4096368 & 1.7909192 \\
bagus & -0.8027187 & -1.6951073 & 2.1159475 \\
semoga & -2.2682748 & -0.8437226 & -1.4933019 \\
lebih & 2.2986956 & -1.6426915 & -2.0371377 \\
lagi & 0.8926442 & 0.8561693 & 0.39170513 \\
\hline
\end{tabular}

\subsubsection{Ekstraksi Fitur Average base Word2vec}

Ekstraksi fitur menggunakan Average base Word2vec setiap komentar terdiri dari kata-kata, setiap kata memiliki nilai vector, nilai vector dari masing-masing kata dari setiap komentar dilakukan rata-rata yang mana sehingga setiap komentar memiliki 100 fitur yang sama. Hasil rata-rata vector tersebut akan mewakili fitur komentarnya saat proses klasifikasi Adapun contoh proses ekstraksi fitur Average base Word2vec pada gambar 1.

\begin{tabular}{|c|c|c|c|c|c|}
\hline Kata & V1 & v2 & v.. & v99 & v100 \\
\hline baik & -3.380503 & -2.8598306 & -3.129318 & 2.4271312 & -3.380503 \\
\hline dan & 1.9481431 & -0.4096368 & -3.1227102 & 1.7909192 & 1.9481431 \\
\hline bagus & -0.8027187 & -1.6951073 & -0.2912473 & 2.1159475 & -0.8027187 \\
\hline
\end{tabular}

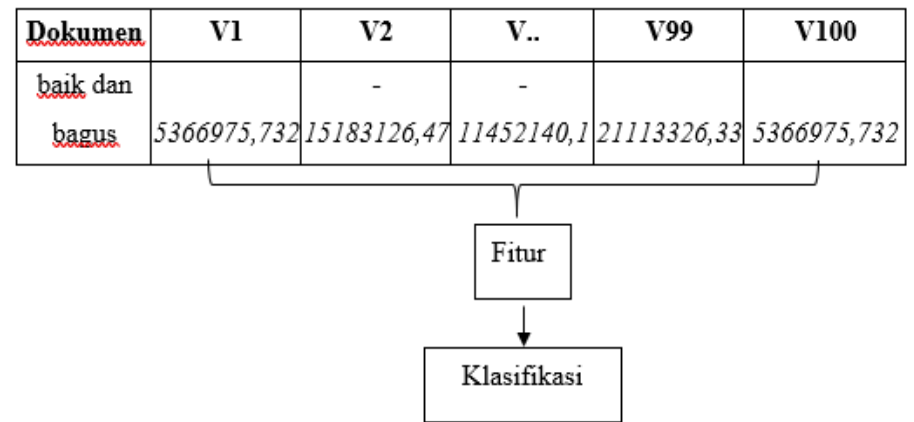

Gambar 1. Proses average berbasis model Word2vec

Ekstraksi fitur menggunakan Average base Word2vec pada analisis sentimen komentar ini memiliki tingkat akurasi sebesar 84,8\%. 
3.1.4 Ekstraksi fitur menggunakan Bag of Centroid base Word2vec.

Pada ekstraksi fitur meggunakan Bag of Centroid base Word2vec setiap kata kita cluster menggunakan algoritma clustering. Pada penelitian ini digunakan dua algoritma clustering yang mana K-Means dan Hirarchical Clustering. Dari setiap kata yang pada data komentar, dilakukan cluster sehingga mendapatkan label cluster. Tahapan cluster vector Word2vec seperti pada gambar 2.

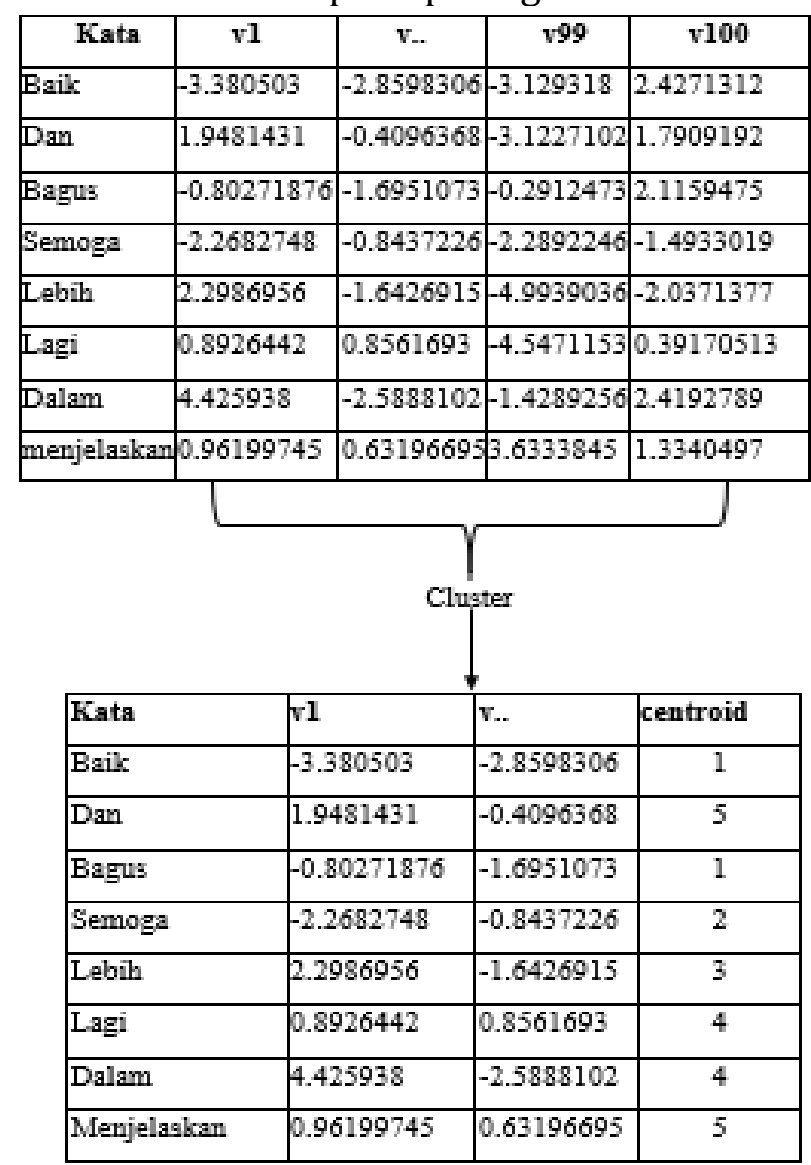

Gambar 2. Pengelompokan kata berdasarkan cluster

Dari kata-kata yang ada pada komentar kita cluster sehingga mendapatkan label berdasarkan centroid yang terkumpul. Adapun hasil kata dengan label centroid terdapat pada tabel 2 .

Tabel 2. Contoh kata dengan lebel centroid

\begin{tabular}{lc}
\hline Kata & Centroid \\
\hline Baik & 1 \\
Dan & 5 \\
Bagus & 1 \\
Agar & 3 \\
Jangan & 2 \\
Terlalu & 3 \\
Cepat & 1 \\
Dalam & 2 \\
Menjelaskan & 3 \\
Soal & 4 \\
\hline
\end{tabular}


Kemudian dari data komentar setiap katanya dikelompokkan berdasarkan centroid yang telah ada. Jika jumlah cluster 5 maka jumlah fitur juga 5 , adapun hasil ekstraksi fitur Bag of Centroid base Word2vec disajikan pada tabel 3.

Tabel 3. Contoh hasil ekstraksi fitur menggunakan Bag of Centroid base Word2vec

\begin{tabular}{llllllll}
\hline Komentar & C1 & C2 & C3 & C4 & C5 & Label \\
\hline $\begin{array}{l}\text { Baik dan bagus } \\
\begin{array}{l}\text { Agar jangan terlalu cepat dalam } \\
\text { menjelaskan soal soal }\end{array}\end{array}$ & 2 & 0 & 0 & 0 & 1 & Positif \\
\hline
\end{tabular}

Kata "baik" berada pada centroid 1 maka C1 yang awalnya 0 ditambah 1, kata "dan" berada pada centroid 5 nilai C1 ditambah 1, kemudian kata bagus berada pada C1 sehingga nilai C1 yang awalnya 1 bertambah 1 sehingga nilai $\mathrm{C} 1=2$. Begitu seterusnya hingga 2823 komentar menjadi fitur yang terstruktur.

Hasil akurasi ekstraksi fitur Bag of Centroid base Word2vec menggunakan algoritma K-Means dengan jumlah fitur yang bervariasi disajikan pada tabel 4 .

Tabel 4. Hasil akurasi dari ekstraksi fitur Bag of Centroid base Word2vec menggunakan K-Means

\begin{tabular}{ll}
\hline Jumlah fitur & Akurasi \\
\hline 30 & 0,667 \\
40 & 0,758 \\
50 & 0,724 \\
60 & 0,785 \\
65 & 0,75 \\
70 & 0,804 \\
75 & 0,758 \\
80 & 0,74 \\
90 & 0,768 \\
\hline
\end{tabular}

Dari tabel 4 dihasilkan grafik akurasi seperti pada gambar 3.

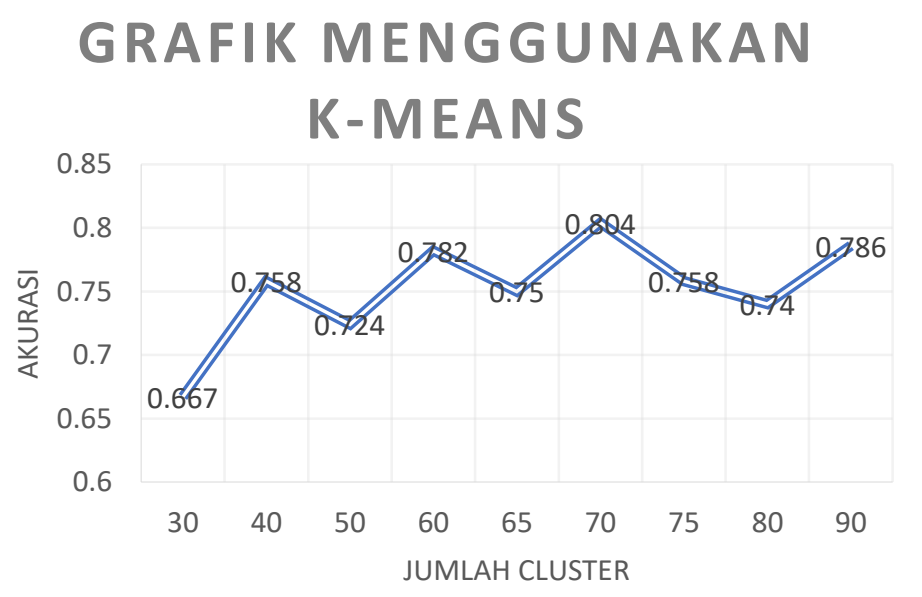

Gambar 3. Grafik akurasi menggunakan K-Means

Dalam menggunakan K-Means diperoleh akurasi terbaik saat jumlah cluster 70 dengan hasil akurasi 0,804. Dari hasil grafik pada gambar 3, jumlah cluster atau centroid tidak berpengaruh banyak dalam hasil kinerja klasifikasi, hal ini 
kemungkinan karena pada algoritma K-Means dalam penentuan nilai $\mathrm{K}$ awal acak sehingga nilai cluster pada setiap prosesnya berbeda-beda. Nilai cluster pada proses ini sangat berpengaruh besar dalam menentukan akurasi klasifikasi.

Karena menggunakan algoritma K-Means hasil akurasinya terbilang kurang terstruktur, dalam penelitian ini dilakukan percobaan menggunakan algoritma clustering lain yaitu Hirarki Clustering dengan metode ward. Hasil menggunakan algortima Hirarki Clustering dengan fitur yang bervariasi terdapat pada tabel 5.

Tabel 5. Hasil akurasi dari ekstraksi fitur Bag of Centroid base Word2vec

\begin{tabular}{cl} 
menggunakan Hirarki Clusteri \\
\hline Lumlah Cluster & Akurasi \\
\hline 30 & 0,708 \\
40 & 0.77 \\
50 & 0.795 \\
60 & 0.793 \\
65 & 0.802 \\
70 & 0.809 \\
75 & 0.816 \\
78 & 0.809 \\
80 & 0.805 \\
90 & 0.8 \\
\hline
\end{tabular}

Berdasarkan tabel 5 diperoleh bahwa jumlah fitur sangat berpengaruh besar terhadap akurasi saat proses klasifikasi dan menghasilkan grafik akurasi seperti pada gambar 4 .

\section{Grafik menggunakan Hirarki Clustering}

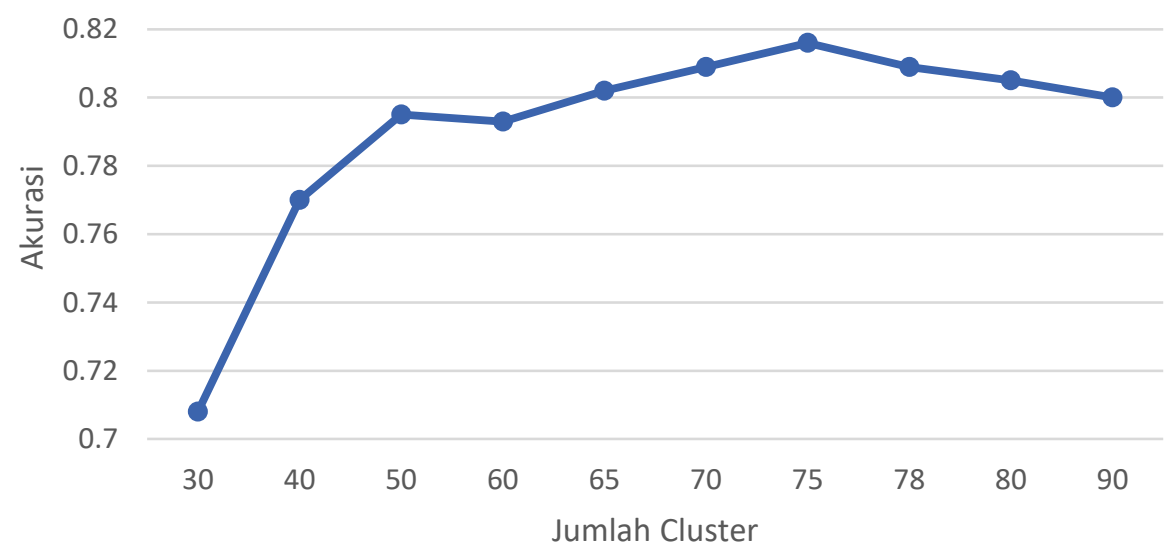

Gambar 4. Grafik akurasi menggunakan Hirarki Clustering

Dengan jumlah fitur yang sedikit menghasilkan akurasi yang rendah. Maka ditambah jumlah fiturnya dan didapatkan akurasi tertinggi pada saat jumlah fitur 75. Hal ini karena pada jumlah fitur 75 kata-kata terkumpul dengan baik, sehingga pada saat sentiment analysis pengenalan pola kata positif dan negatif lebih mudah dipelajari. Adapun hasil perbandingan kinerja algoritma Clustering terdapat pada gambar 5. 


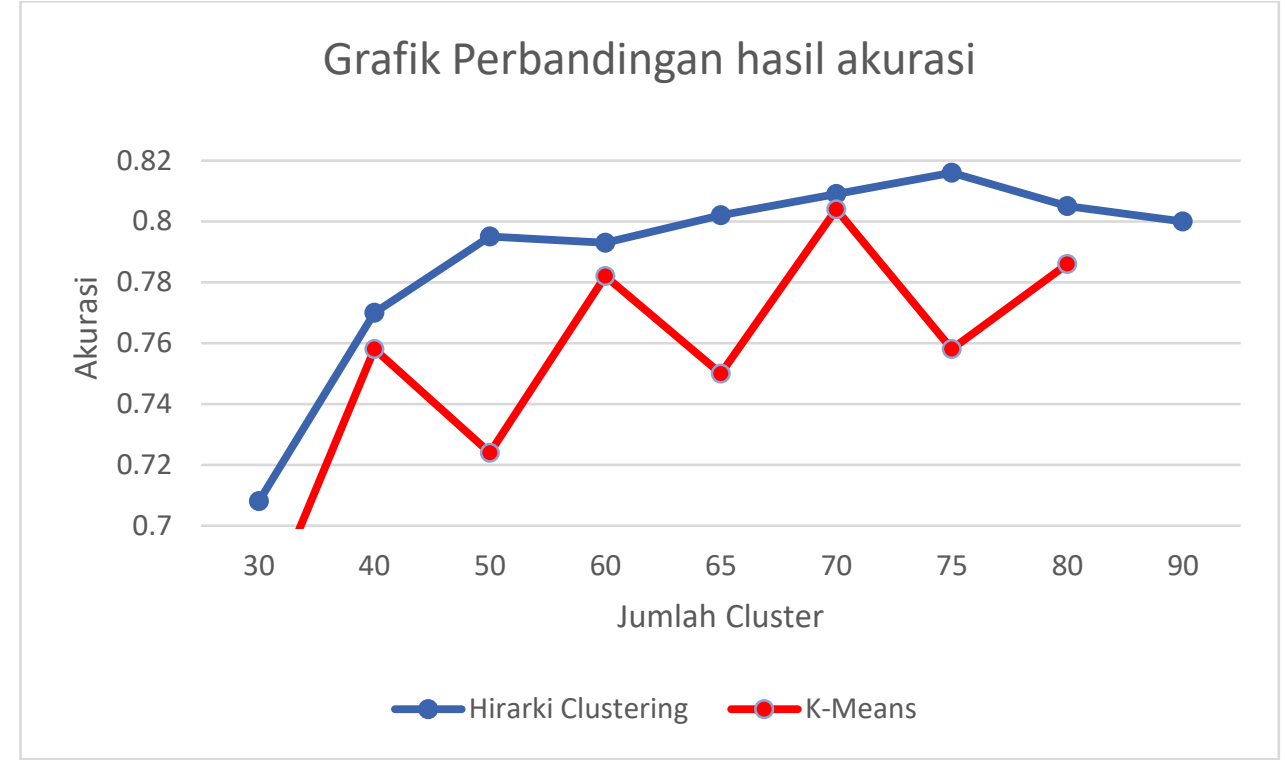

Gambar 5. Perbandingan kinerja algoritma Clustering

3.1.5 Penggabungan Average base Word2vec dan Bag of Centroid base Wor2vec

Pada proses ekstraksi fitur ini data fitur Average base Word2vec digabungkan dengan data fitur Bag of Centroid base Word2vec dengan hasil akurasi terbaik. Adapun fitur terbaik dari Bag of Centroid base Word2vec menggunakan algoritma K-Means 70 dan Hirarki Clustering saat 75 fitur. Contoh penggabungan kedua ekstraksi fitur terdapat pada tabel 6 . 
Tabel 6. Data ekstrksi fitur penggabungan Average base Word2vec dan Bag of Centroid base Wor2vec

\begin{tabular}{llllllllc}
\hline \multicolumn{1}{c}{$\mathrm{v} 1$} & \multicolumn{1}{c}{$\mathrm{v} 99$} & \multicolumn{1}{c}{$\mathrm{v} 100$} & $\mathrm{c} 1$ & $\mathrm{c} 2$ & $\mathrm{C.}$ & $\mathrm{C} 69$ & $\mathrm{C70}$ & label \\
\hline-0.6662942866484324 & 1.462 .751 .516 .699 .790 & 17.697 .981 .670 .498 .800 & 4 & 1 & 0 & 0 & 1 & 1 \\
0.7452152929104426 & 16.522 .573 .049 .125 .400 & 3.556 .856 .980 .328 .170 & 14 & 2 & 2 & 0 & 13 & 0 \\
0.2764149613391895 & 5.972 .464 .731 .679 .510 & 8.642 .235 .655 .051 .010 & 4 & 0 & 1 & 0 & 8 & 0 \\
0.07762888669967652 & 1.728 .857 .127 .428 .050 & 21.251 .153 .630 .018 .200 & 4 & 0 & 0 & 0 & 1 & 1 \\
0.3831836887324849 & 17.952 .925 .089 .746 .700 & 38.554 .589 .971 .899 .900 & 15 & 0 & 2 & 0 & 10 & 1 \\
0.630289527380632 & 3.393 .151 .644 .669 .050 & 6.310 .661 .762 .952 .800 & 7 & 0 & 1 & 0 & 9 & 1 \\
-10.120 .803 .117 .752 .0 & 466.977 .499 .127 .388 & 5.155 .191 .433 .429 .710 & 1 & 0 & 1 & 0 & 0 & 1 \\
0.4611934511100544 & 4.061 .025 .979 .106 .910 & 6.489 .902 .796 .442 .890 & 9 & 2 & 0 & 2 & 4 & 1 \\
0.9527595524604504 & 19.967 .673 .039 .422 .000 & 4.416 .797 .601 .546 .230 & 10 & 0 & 0 & 0 & 14 & 1 \\
18.061 .231 .261 .549 .000 & 63.037 .742 .853 .451 .200 & 9.194 .977 .505 .848 .950 & 6 & 0 & 1 & 0 & 6 & 0 \\
0.3543612376919815 & 5.707 .253 .674 .976 .520 & 7.219 .869 .456 .120 .890 & 3 & 0 & 2 & 1 & 8 & 0 \\
0.4684461589902639 & 29.633 .056 .064 .136 .300 & 58.832 .329 .908 .385 .800 & 7 & 1 & 1 & 0 & 9 & 0 \\
0.30228009703569114 & 11.560 .720 .800 .654 .900 & 13.420 .934 .431 .254 .800 & 2 & 0 & 1 & 0 & 5 & 0 \\
-0.1886933809992942 & 67.772 .256 .000 .475 .400 & 9.275 .476 .082 .482 .120 & 6 & 1 & 1 & 0 & 3 & 0 \\
0.7722111276927448 & 28.048 .856 .489 .005 .500 & 5.721 .197 .124 .038 .420 & 11 & 0 & 5 & 0 & 5 & 0 \\
0.17475399499138194 & 15.046 .192 .423 .750 .900 & 17.326 .621 .236 .590 .000 & 5 & 0 & 0 & 0 & 1 & 0 \\
0.14292659109522554 & 0.3473603802949897 & 20.498 .542 .527 .523 .600 & 20 & 6 & 6 & 1 & 17 & 1 \\
-0.193236369639635 & 4.836 .442 .353 .576 .420 & 4.921 .978 .569 .030 .760 & 1 & 0 & 0 & 0 & 1 & 1 \\
0.2392844571731985 & 24.170 .802 .678 .912 .800 & 24.709 .611 .676 .633 .300 & 2 & 0 & 1 & 0 & 1 & 1 \\
\hline
\end{tabular}


Hasil penggabungan kedua ekstraksi fitur tersebut memperoleh akurasi sebesar 0,846. Ekstraksi fitur penggabungan Average base Word2vec dan Bag of Centroid base Wor2vec memiliki hasil yang tidak lebih baik dari Average base Word2vec. Hasil dari penggabungan kedua ekstraksi fitur dengan data ini memperoleh akurasi sebesar 0,853. Dari hasil tersebut maka dapat disimpulkan bahwa penggabungan ekstraksi fitur menggunakan $\mathrm{K}$-Means mengurangi hasil akurasi, berbeda dengan penggabungan menggunakan Hirarki Clustering meningkatkan akurasi dari Average base Word2vec.

\subsection{Pembahasan}

Data yang digunakan pada penelitian ini merupakan data kolom komentar evaluasi dosen semester genap tahun ajaran 2017/2018 FMIPA ULM dengan jumlah data 9154 data. Untuk membuat model Word2vec digunakan data komentar dan juga data artikel Wikipedia bahasa Indonesia yang berjumlah 36000 artikel sebagai korpus. Setelah melewati proses preprocessing yang mana menghapus file redudansi, menghapus komentar yang tidak menunjukan sentimen, menghapus karakter selain huruf, didapatkan 2823 data dengan 1242 data berlabel positif dan 1581 data berlabel negatif.

Pada model Word2vec setiap kata memiliki nilai vector yang merepresentasikan kata tersebut. Nilai vector tersebut kita gunakan untuk proses ekstraski fitur. Pada penelitian ini kita gunakan Average base Word2vec, Bag of Centroid base Word2vec dan penggabungan keduanya untuk proses ekstraksi fitur yang mana menggunakan model Word2vec yang telah kita buat.Cara kerja ekstraksi fitur menggunakan Average base Word2vec pada dokumen yang kita klasifikasi terdiri dari kata-kata, Setiap kata memiliki nilai vector pada model Word2vec. Adapun jumlah fitur yang digunakan pada Average base Word2vec mengikuti jumlah fitur model Word2vec yang kita latih, yang mana pada penelitian ini digunakan model Word2vec dengan jumlah fitur 100 sehingga jumlah fitur pada ekstraksi fitur Average base Word2vec juga 100 fitur. Ekstraksi fitur menggunakan Average base Word2vec menghasilkan akurasi sebesar 0,848.

Cara kerja ekstraksi fitur menggunakan Bag of Centroid base Word2vec, pertama model Word2vec diklaster menggunakan algoritma clustering dengan metode ward, yang mana pada penelitian ini digunakan algoritma $K$-Means dan juga Hirarki Clustering dengan metode ward. Kemudian kata-kata pada model terkumpul berdasarkan klasternya. Setelah itu kata-kata pada setiap komentar dikelompokan berdasarkan label cluster, kemudian hasil pengelompokan kata pada komentar menjadi fitur untuk dilakukan proses klasifikasi.

Dari hasil menggunakan K-Means dengan beberapa jumlah cluster atau centroid tidak berpengaruh banyak dalam hasil kinerja klasifikasi, hal ini kemungkinan karena pada algoritma $\mathrm{K}$-Means dalam penentuan nilai $\mathrm{K}$ awal acak sehingga nilai cluster pada setiap prosesnya berbeda-beda. Nilai cluster pada proses ini sangat berpengaruh besar dalam menentukan akurasi klasifikasi. Dalam Bag of Centroid base Word2vec menggunakan algoritma K-Means hasil akurasi terbaik pada saat jumlah fitur 70 dengan akurasi 0,804. 
Kemudian untuk ekstraksi fitur Bag of Centroid base Word2vec menggunakan algoritma Hirarki Clustering juga digunakan jumlah fitur yang bervariasi. Ketika jumlah fitur meningkat maka hasil akurasi juga meningkat. Adapun akurasi tertinggi pada saat jumlah fitur berjumlah 75 dengan hasil akurasi sebesar 0,816 . Dengan hasil ini maka algortima Hirarki Clustering memiliki performa yang lebih baik dari pada algortima K-Means. Algoritma Hirarki Clutering dalam hal ini lebih baik dalam mengelompokan kata-kata karena algoritma ini menyusun kata dengan vector yang berdekatan kemudian memotong dalam beberapa bagian sesuai jumlah centroid yang kita tentukan. Berbeda dengan algoritma K-Means yang mana pada algortima tersebut menentukan nilai $\mathrm{K}$ awal dengan acak sehingga cluster pun terkumpul menjadi kurang terstruktur.

Kemudian untuk ekstraksi fitur penggabungan Average base Word2vec dan Bag of Centroid base Word2vec, yang mana 100 fitur Average base Word2vec digabung dengan fitur terbaik Bag of Centroid base Word2vec dalam hal ini menggunakan algoritma Clustering K-Means dengan jumlah fitur 70 memperoleh akurasi 0,846. Dalam hal ini hasil penggabungan ekstraksi fitur tidak lebih baik dari ekstraksi fitur Average base Word2vec. Karena hasil ekstraksi fitur Bag of Centroid base Word2vec menggunakan $K$-Means menghasilkan fitur yang kurang baik.

Ekstraksi fitur Bag of Centroid base Word2vec menggunakan algortima Hirarki Clustering diperoleh kinerja tertinggi pada saat jumlah fitur 75 dengan akurasi 0,816 maka dilakukan penggabungan fitur dengan Average base Word2vec yang mana hasil penggabungan ini menghasilkan akurasi sebesar 0,863. Dari hasil penggabungan ini memperoleh akurasi yang lebih baik dibandingkan dengan Average base Word2vec karena fitur yang dihasilkan algoritma Hirarki Clustering bagus dan juga memberikan informasi terhadap fitur yang lebih lengkap.

Dari hasil penelitian ini didapatkan hasil terbaik ekstraksi fitur menggunakan penggabungan ekstraksi fitur Average base Word2vec dengan ekstraksi fitur Bag of Centroid base Word2vec mengunakan algoritma Hirarki Clustering.

\section{SIMPULAN}

Kesimpulan yang dapat diambil dari hasil penelitian yang telah dilakukan bahwa perbandingan ekstraksi fitur Average base Word2vec dan Bag of Centroid base Word2vec, pada pengujian menghasilkan Average base Word2vec memiliki kinerja yang lebih baik. Penerapan Average base Word2vec pada data komentar evaluasi dosen memiliki akurasi 0,848, Sedangkan Bag of Centroid base Word2vec menggunakan data komentar evaluasi dosen menghasilkan kinerja terbaik dengan akurasi 0,816. Dan penggabungan data ekstraksi fitur Average base Word2vec dan Bag of Centroid base Word2vec menggunakan data komentar evaluasi dosen menghasilkan akurasi 0,853. Untuk penelitian lebih lanjut dapat menggunakan Average base Wordvec dengan jumlah fitur yang bervariasi, dapat menggunakan ekstraksi fitur menggunakan Word2vec yang mana menggabung beberapa kata menjadi satu makna, dengan contoh kata "tidak" dan kata "baik" menjadi "tidak baik" dalam satu makna atau dapat gunakan Stopword Removal agar kata-kata lebih jelas. 


\section{DAFTAR PUSTAKA}

[1] Fauzi, M. Ali, 2019. Word2vec model for Sentiment Analysis of product reviews in Indonesian language, Brawijaya University. Vol. 9, No. 1. page. 525-530.

[2] Rossiello, Gaetano dkk, 2017. Centroid-based Text Summarization through Compositionality of Word Embeddings, University of Bari. Proceedings of the MultiLing 2017 Workshop on Summarization and Summary Evaluation Across Source Types and Genres, pages 12-21 